\title{
RETINOPATIA ASSOCIADA AO USO DE ENROFLOXACINO EM GATOS
}

Jéssica de Lima Mendes ${ }^{1}$, Larissa Jesus Trombetta ${ }^{2}$, Andréia Vitor Couto do Amaral $^{3^{*}}$

1.Graduada em Medicina Veterinária pela Universidade Federal de Jataí, Jataí, Goiás, Brasil.

2. Discente, Medicina Veterinária, Universidade Federal de Jataí, Jataí, Goiás, Brasil.

3. Docente, Medicina Veterinária, Universidade Federal de Jataí, Jataí, Goiás, Brasil. E-mail: andreiavcvet@hotmail.com

Recebido em: 06/04/2019 - Aprovado em: 10/06/2019 - Publicado em: 30/06/2019 DOI: 10.18677/EnciBio_2019A121

As fluorquinolonas são antimicrobianos com ampla aplicação na rotina da medicina veterinária. Dentre estas, destaca-se o enrofloxacino, um fármaco que possui espectro de ação antimicrobiana abrangente no organismo animal. Atualmente é uma das maiores classes de agentes antibióticos utilizadas no mundo para o tratamento de infecções bacterianas, tanto Gram-positivas, quanto as Gramnegativas. Assim, tais características a tornam uma frequente escolha para tratamento de várias enfermidades em cães e gatos. Entretanto, na espécie felina, devido ao aumento da dose, frequência de administração, ou infusões rápidas, juntamente ao desconhecimento dos efeitos colaterais, pode ocasionar a degeneração da retina. Tal degeneração causada pelo tratamento com enrofloxacino manifesta-se como cegueira de caráter agudo, geralmente irreversível. Apesar da fisiopatologia deste processo permanecer desconhecida, existem algumas hipóteses prováveis, tal como a deficiência de proteína ABCG2 na barreira hemato retiniana dos gatos, propiciando o acúmulo do fármaco na retina e a ocorrência das alterações posteriores. Os sinais clínicos mais comuns incluem midríase com ausência de reflexos pupilares, relutância ao andar ou pular, hiperreflexia tapetal e atenuação dos vasos retinianos. O diagnóstico pode ser realizado através de exames oftálmicos como a oftalmoscopia direta, analisando o padrão de alterações do fundo de olho, e a eletreorretinografia, que fornece dados captados dos fotorreceptores confirmando a cegueira dos animais. Como não há um tratamento, a profilaxia é a melhor opção para evitar a degeneração de retina nos gatos. 0 presente trabalho tem como objetivo elaborar uma revisão, que relacione o uso de enrofloxacino em gatos e a degeneração de retina.

PALAVRAS-CHAVE: cegueira, fluorquinolonas, felinos 


\title{
ENROFLOXACIN-ASSOCIATED RETINOPATHY IN CATS - LITERATURE REVIEW
}

\begin{abstract}
Fluoroquinolones are antimicrobial agents with wide application in the routine of veterinary medicine. Among them, highlights enrofloxacin, a drug that has a broad range of antimicrobial action in the animal organism. It is currently one of the largest classes of antibiotic agents used in the world for the treatment of bacterial infections, both Gram-positive and Gram-negative. Thus, such characteristics make it a frequent choice for the treatment of various diseases in dogs and cats. However, in the feline species, due to increased dose, frequency of administration, or rapid infusions, together with the lack of knowledge of side effects, can lead to retinal degeneration. Such degeneration caused by treatment with enrofloxacin manifests as acute blindness, usually irreversible. Despite the pathophysiology of the abnormality process, there were some probable hypotheses, such as a protein ABCG2 deficiency in the retinal retraction of the cats, leading to accumulation of drug in the retina and the occurrence of subsequent changes. The most common clinical indicators are absence of pupillary reflexes, reluctance to walk or jump, hyperreflexia, and retinal vessel attenuation. The diagnosis can be made through ophthalmic exams such as direct ophthalmoscopy by analyzing the pattern of alterations of the fundus of the eye, and eletreoretinography, which provides data captured from the photoreceptors confirming the blindness of the animals. As there is no treatment, prophylaxis is the best option to avoid retinal degeneration in cats. The present work aims to elaborate a review, which relates the use of enrofloxacin in cats and retinal degeneration.
\end{abstract}

KEYWORDS: blindness, fluoroquinolones, feline

\section{INTRODUÇÃO}

Os quimioterápicos antibióticos da classe das quinolonas são considerados o centro de interesse clínico desde a sua descoberta na década de 60. São vistos como antibióticos ideais pois seus representantes permeiam a vários atributos: apresentações para uso tópico, oral e parenteral, alta potência, amplo espectro, boa disponibilidade, alta concentração sérica e grande distribuição nos tecidos. Além da baixa incidência de efeitos colaterais quando usado da forma correta (ANDERSON; MACGOWAN, 2003).

O método de classificação das quinolonas mais encontrado na literatura é a classificação através de gerações, tratando-se de quatro gerações, divididas de acordo com o espectro antimicrobiano e suas indicações terapêuticas. As fluorquinolonas constituem um tipo de quinolona, caracterizadas pela adição de flúor na sua composição química (SILVA; HOLLENBACH, 2010).

Conforme Anjos e Brito (2009), o enrofloxacino é uma fluorquinolona amplamente utilizada na medicina veterinária. Entretanto, sugere-se a degeneração de retina como um efeito adverso encontrado em gatos que a utilizaram em tratamentos. Ainda que o processo causador da degeneração retiniana pelo uso do enrofloxacino não estar claramente definido, acredita-se que alguns fatores podem predispor essa alteração como altas doses da droga, exposição à luz solar durante o tratamento, infusão intravenosa rápida, longos períodos de uso, interações medicamentosas, idade e o acúmulo da droga devido ao seu metabolismo alterado ou eliminação reduzida (CAVALVANTE et al. 2009).

Por essa falta de elucidação quanto ao tema, surge a necessidade de realizar uma revisão bibliográfica com o objetivo principal de relacionar o uso de 
enrofloxacino e a degeneração de retina em gatos, visando contribuir no conhecimento para futuros estudos referentes ao tema. Este trabalho teve como objetivos específicos: Discorrer sobre as características farmacológicas das fluorquinolonas, em especial do enrofloxacino; discorrer sobre a fisiopatologia, diagnóstico e prevenção da retinopatia associada ao uso do enrofloxacino em gatos; e informar sobre a importância da prescrição e utilização do enrofloxacino com atenção e cuidados necessários na rotina da clínica de felinos.

O médico veterinário deve saber diferenciar as particularidades dos felinos frente as outras espécies. Frente ao exposto, justifica-se o interesse pelo tema, devido ao surgimento da necessidade de investigar também as particularidades dos gatos que favorecem as intoxicações medicamentosas.

Assim, acredita-se que o desenvolvimento dessa revisão possa contribuir significativamente em estudos futuros acerca desta temática, e proporcionar a reflexão ao profissional médico veterinário sobre a importância das particularidades metabólicas dos gatos.

\section{Propriedades das fluorquinolonas}

As fluorquinolonas constituem um grupo de substâncias químicas com ação antibacteriana. São caracterizadas pela adição de flúor na sua composição química (Figura 1). São conceituadas como antibióticos, relativamente seguras para humanos e animais domésticos. Os principais representantes deste grupo são enrofloxacino, ibafloxacino, marbofloxacino e orbifloxacino (todos de uso exclusivo em medicina veterinária), norfloxacino, ciprofloxacino, ofloxacino, lomefloxacina e perfloxacina na medicina humana (BARCELLOS et al., 2006; SILVA; HOLLENBACH, 2010; FORESTI, 2015).

As fluorquinolonas de primeira geração são representadas pelo ácido nalidíxico, a flumequina e o ácido oxonílico. Na época da descoberta, estas drogas foram efetivas somente para o tratamento de infecções urinárias. As quinolonas de segunda geração foram obtidas na década de 80 a partir da adição de um átomo de flúor na posição 6 e 7 (grupo piperazinil), do núcleo das quinolonas, e deram origem a moléculas com considerável aumento de atividade antibacteriana. São exemplos da categoria: o norfloxacino, ciprofloxacino, ofloxacino e enrofloxacino. As quinolonas de terceira geração apresentam espectro de atividade balanceado, sendo indicados basicamente no tratamento de infecções respiratórias como levofloxacino e gemifloxacino. A maior atividade contra patógenos Gram (-) é encontrada na quarta geração, estes ainda apresentam atividade aumentada contra Gram (+) e patógenos do trato respiratório. Como exemplos podem ser citados o moxifloxacino e sitafloxacino (HIGGINS et al., 2003, CAVALCANTE et al. 2009, FORESTI, 2015; SPINOSA et al., 2017). 

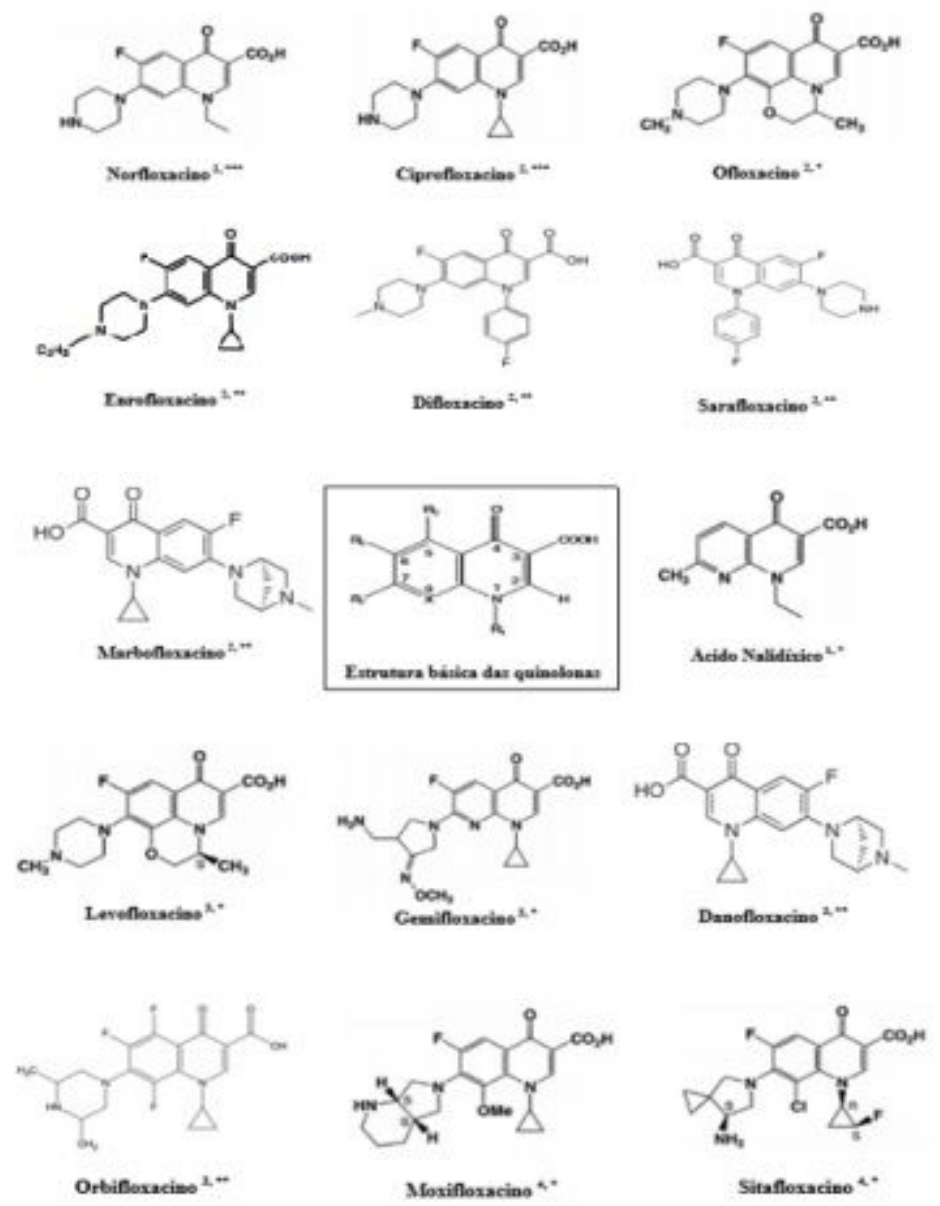

1-Primeira geração; 2-Segunda geração; 3-Terceira geração; 4-Quarta geração:

*Uso humano; **Uso Veterinário; *** Uso humano e veterinário

FIGURA 1: estrutura química das fluorquinolonas e suas gerações. Fonte: FORESTI, (2015)

\section{Farmacodinâmica}

Conforme Tavares (2014), o mecanismo de ação das fluorquinolonas é caracterizado pela interferência na síntese do DNA bacteriano, através da inibição de duas enzimas: DNAgirase e Topoisomerase IV, que tem como função o controle do processo de divisão a reunião de novas cadeias no enovelamento do novo DNA bacteriano durante a replicação. Foresti (2015) acrescenta que, durante este processo, o DNA bacteriano se relaxa e suas espirais ocupam um espaço maior do que o limite da célula bacteriana, sendo que as extremidades livres do DNA induzem a síntese de proteínas, a produção de exonucleases e degradação dos cromossomos, fatores que resultam na morte celular bacteriana.

Nesse sentido, as fluorquinolonas vão exibir diferentes ações antibacterianas de acordo com o pH e as suas estruturas. Nas bactérias Gram-negativas, ocorre entrada por meio das porinas do microrganismo. Nas bactérias Gram-positivas, ocorre difusão via membrana celular interna (SILVA; HOLLENBACH, 2010). 


\section{Farmacocinética}

No que se refere à farmacocinética das fluorquinolonas, após a administração por via oral (principal via de administração), são rapidamente absorvidas por animais monogástricos. Por outro lado, o pico máximo de concentração sérica varia conforme a espécie animal (SILVA; HOLLENBACH, 2010; FORESTI, 2015).

Segundo Silva e Hollenbach (2010), os efeitos adversos do uso das quinolonas em cães e gatos podem variar, sendo que, os mais comuns são vômito, diarreia e dor abdominal. Apesar de não ser comum, podem ocorrer reações alérgicas apresentando urticária, eosinofilia, ocorrência de pápulas e febre. Tavares (2014) acrescentou que podem ocorrer, também, alterações do sistema nervoso central, dependendo da dose e a frequência da administração do fármaco, apresentando sonolência, cefaleia, insônia, fadiga, depressão e convulsão, e são mais frequentes em animais idosos e lactentes.

Devido a sua intensa utilização nos gatos, para diversos tratamentos de infecções bacterianas, têm sido descritos casos de cegueira aguda e irreversível decorrente do uso de quinolona: o enrofloxacino. Esta alteração ocorre devido à degeneração de retina, não sendo observada com as demais quinolonas. Os felinos apresentam maior vulnerabilidade da barreira hematoencefálica quando comparado às demais espécies domésticas. Esta característica, somada à lipossolubilidade do medicamento, à alta dose ou aumento da frequência de administração, pode levar ao acúmulo do enrofloxacino no sistema nervoso central dos felinos, potencializando o risco de cegueira (SPINOSA et al., 2017).

\section{O Enrofloxacino}

Conforme Foresti (2015), o enrofloxacino é um fármaco antimicrobiano da classe das fluoroquinolas de segunda geração, com a fórmula: 1-ciclopropil-7-(etil-1piperazinil)-6-fluoro-1, 4dihydro-4-oxo-3- ácido quinolonacarboxílico (Figura 2). Foi a primeira quinolona a ser introduzida na medicina veterinária desde 1989, abrangendo diversas espécies animais e produzida em diferentes formas farmacêuticas. O principal metabólito ativo do enrofloxacino é o ciprofloxacino, ambos possuem caráter anfótero, com valores de pka1 entre 5,5 e 6,0 e pka2 entre 7,7 e 8,7 .

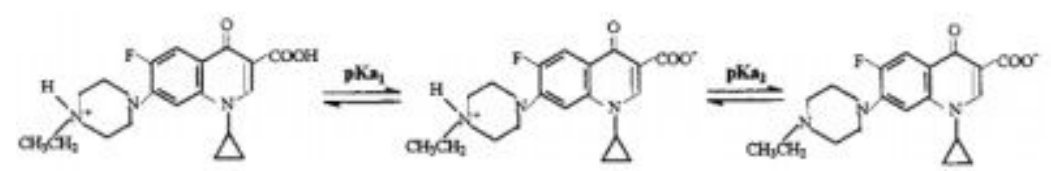

FIGURA 2: Fórmula estrutural do enrofloxacino. Fonte: FORESTI, (2015).

Possui boa disponibilidade oral, favorável difusão para os tecidos, uma meia vida maior e uma toxicidade consideravelmente reduzida, além de um mecanismo de ação bastante abrangente, bem como um amplo espectro de ação contra bactérias Gram-positivas e Gram-negativas. Devido a tantas vantagens e boa distribuição no organismo animal, levou a um extensivo uso na rotina clínica de cães e gatos, sendo indicada para tratamento de vários processos infecciosos, tais como infecções respiratórias, gastrointestinais, urinárias, piodermatites, otites, entre outros 
processos infecciosos (CAVALCANTE et al. 2009; SILVA; HOLLENBACH, 2010; MELO et al., 2014).

O mecanismo de ação do enrofloxacino é característico da classe das fluorquinolonas. Ocorre interferência na síntese do DNA bacteriano, através da inibição de duas enzimas: DNAgirase e Topoisomerase IV, que tem como função o controle do processo de divisão a reunião de novas cadeias de DNA (SILVA; HOLLENBACH, 2010; MELO et al., 2014).

Quanto à farmacocinética, o enrofloxacino é bem absorvido e distribuído quando administrado por via oral, sendo excretado pela urina e pelas fezes em altas concentrações. A biotransformação no organismo ocorre por N-desalquilação, se convertendo em ciprofloxacino. O volume de distribuição é alto na maioria das espécies animais. Concentra-se, sobretudo na saliva, secreção nasal, mucosas, epitélio e secreção bronquial, assim como no fígado e no trato urinário. Transpõe efetivamente o tecido pulmonar, fluido de revestimento e macrófagos alveolares, resultando assim em concentrações maiores que as séricas (SPINOSA et al. 2011).

De acordo com Spinosa et al. (2011), o enrofloxacino é preferencialmente administrado em comprimidos por via oral e é rapidamente absorvido com uma biodisponibilidade de cerca de $83 \%$ em cães e $92 \%$ em gatos, demonstrando a eficácia. A dose recomendada é de $2,5 \mathrm{mg} / \mathrm{kg}$, via oral, a cada 12 horas. Porém, a tendência popular de administrar antibióticos bactericidas em apenas uma dose diária, influenciou o fabricante do enrofloxacino a alterar a dose. Assim, uma dose variável de 5 a $20 \mathrm{mg} / \mathrm{kg}$, uma ou duas vezes ao dia foi adicionada na bula do medicamento.

Alguns estudos têm mostrado efeitos tóxicos do enrofloxacino em diversos tecidos. Foram relatadas inibição da proliferação celular, indução da apoptose e fragmentação do DNA em células do tendão e condrócitos em cães e cavalos. Em gatos, o fármaco tem sido associado à degeneração retiniana irreversível e cegueira por intoxicação medicamentosa (GURBAY et al. 2006; FORD et al, 2007; CAVALCANTE et al. 2009; MELO et al. 2014).

\section{Particularidades no metabolismo dos gatos}

Conforme Anjos e Brito (2009), a intoxicação medicamentosa é o tipo que mais ocorre em felinos, o qual pode ocorrer pela ingestão acidental ou administração de um medicamento sem um conhecimento prévio. Outra problemática da terapêutica felina é a extrapolação de doses e embasamento nas indicações terapêuticas dos fármacos de outras espécies, em particular o cão. As doses de muitos medicamentos, para terapêutica de felídeos, são obtidas a partir das utilizadas para cães, ocasionando uma série de reações adversas. Essas reações se manifestam de várias maneiras, conforme dose utilizada, tipo de fármaco, via de administração, idade e condição física do animal, devido às diferenças no metabolismo entre as espécies. Por estes motivos são relatados tantos casos de intoxicações na clínica de felinos (WIEBE et al., 2002; CAVALCANTE et al. 2009; TREPANIER ,2016).

É necessário lembrar que os felinos possuem diferenças fisiológicas relacionadas ao metabolismo, tais como a deficiência da enzima glicuranil transferase, responsável pela biotransformação de muitos fármacos, além da maior propensão da hemoglobina do felino em se oxidar, resultando em metahemoglobinemia e corpúsculos de Heinz (TREPANIER, 2016).

Assim, torna-se imprescindível o conhecimento acerca da farmacocinética e da farmacodinâmica, além de particularidades do fármaco que o médico irá 
prescrever ao paciente felino, atentando-se quando são utilizadas doses repetidas, uma vez que, caso a concentração estiver saturada, a meia vida do fármaco no organismo pode aumentar, o que agravará os efeitos tóxicos. Podem ocorrer erros nas prescrições, visto que muitos medicamentos ainda carecem de protocolos específicos para os gatos (SOUZA, 2003; ANJOS; BRITO, 2009).

\section{Anatomofisiologia ocular}

Os olhos são órgãos sensoriais, compostos por estruturas diversas, as quais encarregam da proteção, nutrição, acomodamento e percepção da luz para poder focar a imagem de algum ser visual. Cada um possui uma camada de receptores, um sistema de lentes para focalizar a luz, oito nervos condutores de impulsos que transmitem sinais ao cérebro para serem convertidos em visão de cores (KLEIN, 2014; MILLER, 2017).

Conforme Oriá et al. (2011), o olho é formado pelas túnicas fibrosa, vascular e nervosa, além da lente, humor aquoso, humor vítreo e estruturas acessórias, tais como pálpebras, tapete lucidum, conjuntiva, aparelho lacrimal e músculos extraoculares. A órbita ocular separa o olho da cavidade craniana, envolve e protege o olho.

O bulbo ocular encontra-se no interior da órbita, com as pálpebras oferecendo proteção anterior. É composto por três camadas, a primeira e mais externa é composta pela córnea e esclera transição entre ambas denominada de limbo esclerocorneano. Ele é aproximadamente esférico em cães e gatos e o tamanho varia entre as espécies e raças (GELLAT, 2013; TURNER, 2010; ORIÁ et al.,2011; LEITE et al.,2013; MILLER, 2017).

A esclera compõe a túnica fibrosa, e dá suporte ao bulbo pela proteção física do conteúdo intraocular contra agentes externos. A córnea, é formada por epitélio espesso, membrana de Descemet e epitélio posterior ou endotélio. A nutrição é garantida pela difusão de nutrientes e oxigênio pelos vasos perilímbicos, humor aquoso (câmara anterior) e filme lacrimal pré-corneal. No gato, a córnea ocupa cerca de $30 \%$ da camada externa do bulbo ocular e apresenta uma forma cónica. É transparente, ausente de vasos e rica em inervação, possui ramo oftálmico do nervo trigêmeo. Portanto, a córnea, torna-se o tecido ocular mais sensível à dor (SAMUELSON, 2013; LEITE et al.,2013).

A região de transição entre a córnea e a esclera é denominada limbo. Esta área é caracterizada pelo início de pigmento e vasos sanguíneos, e é o principal local de onde partem os vasos para suprimento vascular nos processos de inflamação e reparação corneais. A lente, ou cristalino, é uma estrutura esférica, localizada próximo ao equador do bulbo. Trata-se de uma estrutura cristalina, composta de $65 \%$ de água e $35 \%$ de proteínas (SILVA et al., 2013).

A camada intermediária é formada pelo trato uveal (íris, corpo ciliar e coroide) e a última e mais interna é a camada nervosa, formada pela retina e parte do nervo óptico. Inclui nesta os meios transparentes do globo ocular, humor aquoso, lente e humor vítreo. O conjunto composto por íris e corpo ciliar caracteriza a úvea anterior; e a coroide, a úvea posterior. A íris é a principal estrutura que separa a câmara anterior da posterior, havendo comunicação entre elas apenas pela pupila, por onde flui o humor aquoso (MILLER, 2017).

O corpo ciliar é estruturalmente dividido em pars plicata e pars plana. A pars plicata, compreende os processos ciliares, que são projeções digitiformes. É nesta porção, que permite o posicionamento correto da lente. A pars plana localiza-se logo posteriormente e é relativamente avascular. O humor aquoso, secretado pelo corpo 
ciliar, é um fluido composto por glicose, oxigênio e aminoácidos, resultante da filtração e secreção ativa das células epiteliais ciliares (SILVA et al., 2013).

A coroide é uma estrutura composta por camadas, de externa para internamente, pela supracoroide, camada vascular, tapetum lucidum (camada reflexora), camada coriocapilar e lâmina basal. A camada coriocapilar é a camada vascular mais interna, que faz o suprimento de oxigênio para as camadas mais externas da retina. A camada supracoroide consiste em uma membrana elástica com tecido conjuntivo pigmentado, desprovida de vasos sanguíneos, e encontra-se entre a porção externa dos grandes vasos e a esclera (MILLER, 2017).

O Tapetum lucidum é uma camada uveal com propriedades refletoras, sendo celular nos cães e gatos. Nos cães, este material é composto por guanina, colesterol, zinco e cisteína; e nos gatos, por riboflavina, pteridina e outros lipídeos. Sua função é aprimorar a captação da quantidade de luz que atravessa todas as camadas retinianas (LEITE et al.,2013).

As pálpebras têm função de proteção mecânica e luminosa do globo ocular. Contribui, também, na secreção, na distribuição e na drenagem da lágrima. São constituídas por quatro camadas: pele; músculo orbicular do olho; camada de tecido conjuntivo, formando a conjuntiva palpebral. Possui a porção superior e inferior, são móveis e delgadas que se juntam cobrindo os olhos e formando seus ângulos, medial e lateral (SILVA et al., 2013).

Silva et al. (2013) afirmaram que os cílios protegem o olho contra a luz excessiva e a entrada de pequenas partículas. $E$ a outra estrutura próxima, a terceira pálpebra, tem origem na porção ventromedial da órbita, é formada por uma cartilagem e coberta pela conjuntiva, fornecendo sustentabilidade ao conjunto ocular.

O aporte sanguíneo é feito pela artéria oftálmica externa, dando origem as artérias ciliares posteriores longas, continuando através da artéria circular ciliar, artéria circunlimbal e artéria circular da íris. Já a retina é irrigada pelas artérias ciliares posteriores curtas que formam internamente as artérias da retina (LAUS et al., 2004).

\section{Anatomia e Fisiologia da retina}

A retina é uma membrana delgada que recobre o interior do bulbo ocular, desde a margem pupilar da íris até o disco óptico. Possui estrutura muito complexa composta por 10 camadas. O nervo óptico e a retina são derivados da parte frontal do cérebro (MILLER, 2017).

A retina sensorial está ligada ao cérebro pelo nervo óptico e das suas vias ópticas. Existem as células fotorreceptoras especializadas, os cones e os bastonetes, que contêm fotopigmentos que mudam conforme a exposição a luz e produzem energia química. Esta energia é convertida em energia elétrica, que em último momento é transmitido para o córtex visual do cérebro (GELATT et al., 2013).

Os cones servem para a visão colorida enquanto os bastonetes respondem a todo o espectro visual, e fazem conexões sinápticas diretas com as células bipolares, os quais conectam os receptores com as células ganglionares. Os axônios das células ganglionares conduzem potenciais de ação para o cérebro, através dos nervos ópticos e do humor vítreo (CUNNINGHAM, 2004).

O humor vítreo é um dos meios de transporte do bulbo ocular. Fornece uma pressão que é fundamental no posicionamento da retina, exercendo uma força contra o epitélio pigmentar desta estrutura (GELATT, 2003, LEITE et al., 2013; MILLER, 2017). Dessa forma, conclui-se que a retina tem uma das mais altas taxas 
de metabolismo de qualquer tecido do corpo, se uma fonte de nutrição é interrompida, ou alguma substância estranha se acumular na estrutura e prejudicar as funções celulares, irá ocorrer uma isquemia, o que pode levar a completa perda da função retiniana (GELATT et al., 2013; MILLER, 2017).

\section{Etiologia e fisiopatologia da degeneração retiniana}

Por fatores ainda desconhecidos em pesquisas, acredita-se que a degeneração retiniana associada ao uso de enrofloxacino nos felinos tem sido associada a fatores que podem predispor a essa alteração, e aumentar a severidade da degeneração de retina, tais como: altas doses da droga, ou no plasma, longos períodos de administração, exposição à luz solar durante o tratamento, infusão intravenosa rápida, interações medicamentosas, idade e o acúmulo da droga devido ao seu metabolismo alterado ou eliminação reduzida. Assim, controlando-se esses fatores, autores de diversos estudos afirmam que seria possível diminuir as chances da ocorrência de danos à retina felina (WIEBE et al., 2002; CAVALVANTE et al. 2009).

Várias são as suposições sobre os efeitos das fluorquinolonas nos olhos de gatos. Quanto a fisiopatologia, estudos indicam que a retinopatia causada pelo uso de enrofloxacino é devido a droga ter afinidade pelos tecidos retinianos (SPINOSA et al., 2017). Cavalcante et al. (2009) discorreram que, as fluorquinolonas, em geral, possuem estrutura química similar aos compostos que foram associados à toxicose do nervo óptico, incluindo a cloroquina, que parece ser dose dependente e é irreversível.

A cloroquina, na forma de difosfato, tem alta afinidade pela melanina e se acumula nos lisossomos das células do epitélio pigmentar da retina, que leva a inibição das enzimas lisossomais e possível morte celular. Logo em seguida, ocorre absorção da luz UVA na estrutura onde se encontra a cloroquina, e ocorre degradação de tecido e formação de produtos citotóxicos, os quais parecem responsáveis pelo dano; o grau de dano é dose e tempo dependente (CAVALCANTE et al., 2009).

Wiebe et al. (2002) relataram que a incidência da degeneração é aumentada quando o enrofloxacino é associado a drogas como a furosemida e a cimetidina, que aumentam as concentrações plasmáticas das fluorquinolonas devido a diminuição da excreção renal. Cavalcante et al. (2009), afirmaram que infecções do trato urinário ou hepático concomitantemente ao dano renal pode ter um efeito substancial da disposição da droga, mesmo em gatos jovens, causando acúmulo da droga no organismo mais facilmente.

Um estudo de Gellat et al. (2001) indicou que a administração intravenosa de enrofloxacino pode ser um fator de indução de degeneração retiniana. Foi feito um estudo com 17 gatos, e sete desenvolveram toxicose após terem recebido o fármaco. Isso aconteceu devido ao pico de concentração plasmática ser alcançado rapidamente, o que resultaria em grandes concentrações da droga penetrando na retina e levando à degeneração do tecido retiniano. Os autores afirmaram que isso poderia indicar que a degeneração retiniana pode ser concentração-dependente.

Ainda no estudo realizado por Gellat et al. (2001) puderam ser observadas várias alterações oculares decorrentes da intoxicação por enrofloxacino em gatos, tais como midríase, ausência de reflexos, e cegueira. Verificaram, também, aumento da refletividade tapetal e atenuação do diâmetro dos vasos sanguíneos da retina em gato como ilustrado na Figura 3A (caso em que foi administrado 24 dias de enrofloxacino) e perda de vasos retinianos após 196 dias de tratamento (Figura 3B). 

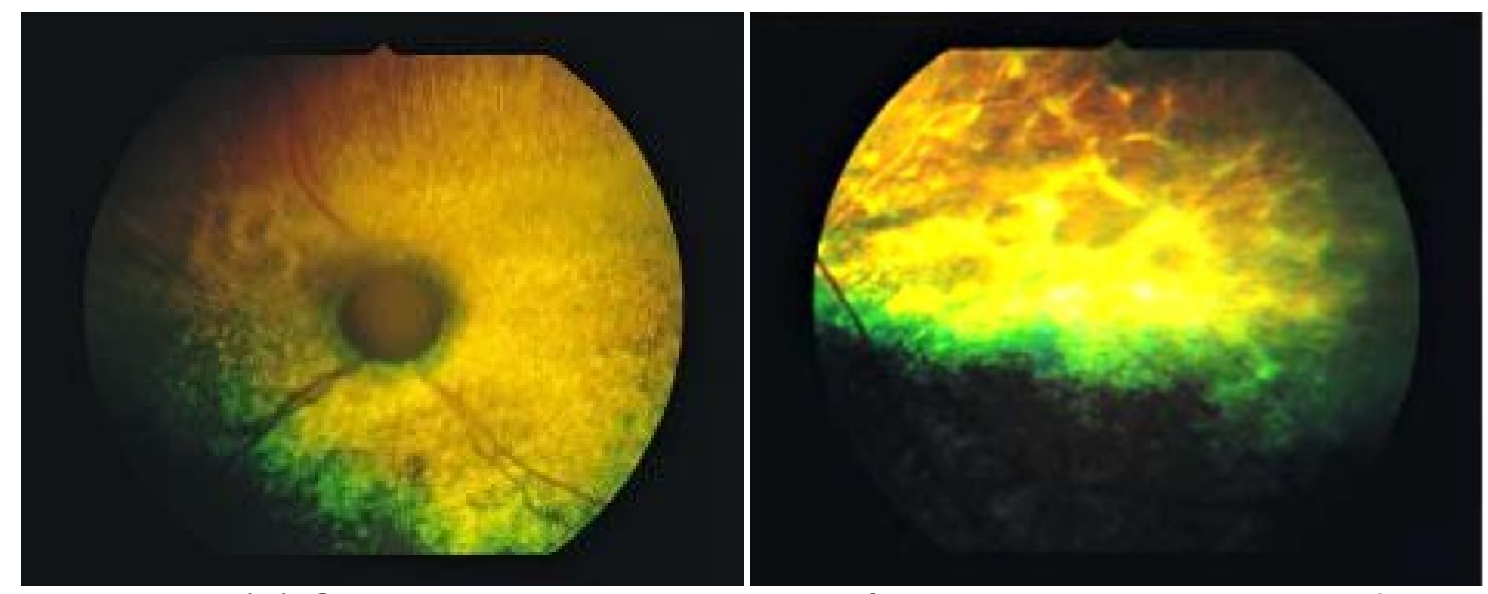

FIGURA 3: (A) Observa-se granularidade da área tapetal, aumento da refletividade e uma moderada atenuação dos vasos retinianos. (B) Perda dos vasos retinianos, refletividade focal aumentada e focos de ferrugem pela área de fundo tapetal.

FONTE: GELLAT et al. (2001).

Anormalidades neurológicas foram relatadas num estudo feito por Ford et al. (2007), onde ocorriam mudanças de comportamento evidentes nos gatos tratados com enrofloxacino, tais como epilepsia, e nistagmo. Tais alterações pioraram com o aumento da administração da droga. $O$ estudo foi feito com 24 gatos, divididos em dois grupos, sendo um de controle, outro de tratamento, cada um contendo 12 animais (6 machos e 6 fêmeas) e divididos novamente em grupos por período de tratamento, 3, 5 e 7 dias todos recebendo a dosagem de $50 \mathrm{mg} / \mathrm{kg}$ uma vez ao dia. Além da cegueira foi observado diminuição no consumo de alimento e queda do peso corporal desses animais. Os achados dos exames clínicos, a oftalmoscopia e a ERG mostraram perda dos bastonetes com progresso de perda de cones, as mudanças estavam correlacionadas com a duração do tratamento. Porém constatou-se que, após a terceira dose, a degeneração de retina se tornou evidente.

Nas imagens de oftalmoscopia foi realizado um estudo comparativo entre um grupo controle (Figura 4A) com os demais grupos que estavam sob tratamento com enrofloxacino por três dias (Figura 4B), cinco dias de tratamento (Figura 4C) e sete dias (Figura 4D) (FORD et al., 2007). 

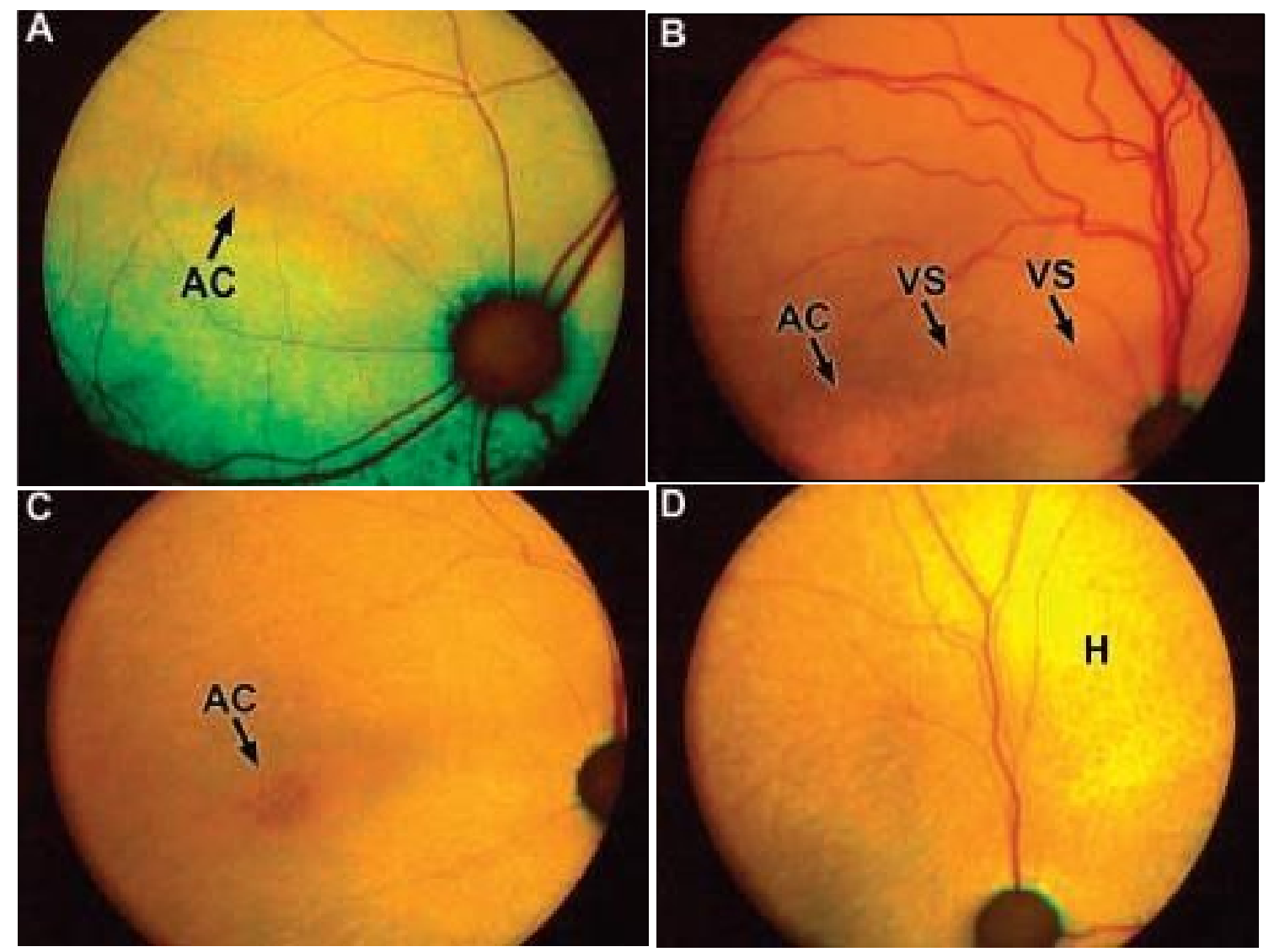

FIGURA 4: (A) Imagem do fundo ocular de uma animal do grupo controle que não recebeu medicamento.(B) llustra alterações de um animal do grupo que recebeu medicação por 3 dias. (C) Imagem se referindo ao grupo que recebeu medicação por 5 dias. (D) Demonstra alterações observadas no grupo de tratamento por 7 dias.

FONTE: FORD et al. (2007)

Dessa forma, ainda é desconhecida a etiologia da degeneração de retina veiculada ao uso do enrofloxacino. Alguns autores apontam que a barreira hematoencefálica do felino tem afinidade pela porção lipofílica do fármaco, fazendo com que as altas concentrações se acumulem no sistema nervoso (SPINOSA et al., 2017).

Outras pesquisas afirmam que esta alteração retiniana tem embasamento genético, pois os gatos possuem uma deficiência na proteína ABCG2 (proteína ligante de ATP 2 da subfamília G). Tal proteína funciona como parte da barreira hemato retiniana impedindo a entrada de substâncias estranhas (LITTLE, 2016). A barreira hematorretiniana possui duas camadas, sendo a mais interna formada por células endoteliais capilares da retina e a mais externa consiste em células epiteliais pigmentadas da retina. Atua na regulação do intercambio de vários compostos como nutrientes, drogas e toxinas, entre o sangue sistêmico e a retina. A proteína ABCG2 atua como um transportador de efluxo, como composto sensíveis a luz. O mecanismo de eliminação das fototoxinas para fora da retina ainda é desconhecido (ASASHIMA et al. 2006; CAVALCANTE et al., 2009). 


\section{Sinais clínicos da degeneração de retina}

Durante a realização da consulta, os tutores fornecem detalhes do que ocorre com 0 animal, sua condição de vida, as alterações observadas e as medicações que foram administradas. O exame físico geral constitui um passo importante, pois proporciona uma visão geral do estado do animal. De forma que se inicie avaliando a postura, seu comportamento, o estado nutricional em que se encontra, aspecto das mucosas visíveis e tempo de preenchimento capilar, avaliação dos parâmetros vitais como frequência cardíaca e respiratória, além da temperatura (ANDRADE, 2008). Após a observação de indícios da perca de visão dos animais, se inicia o exame físico específico oftalmológico (LAUS et al., 2004).

Os sinais clínicos da retinopatia por enrofloxacino incluem uma diminuição da visão e um início agudo de midríase, que é muitas vezes o primeiro sinal notado pelos tutores. Reflexo pupilar à luz ainda pode estar presente, embora lenta e incompleta, ou mesmo ausente. As alterações oftálmicas dessa intoxicação estão associadas à hiperreflexia, alterando assim o diâmetro do nervo óptico e a perca dos vasos sanguíneos. O fundo de olho pode parecer normal no exame inicialmente, embora os sinais de degeneração da retina possam desenvolver-se dentro de alguns dias de administração de enrofloxacino (GELATT et al., 2001).

A degeneração retiniana geralmente é difusa e bilateral. Pode ser observada também atrofia de nervo óptico, e alterações no eletrorretinograma como redução da amplitude da onda b. Na maioria dos casos, a cegueira tem sido permanente, embora alguns gatos têm mantido alguma visão. Uma das descobertas importantes da presente toxicidade é a rapidez com que a retina se degenera (GELATT et al., 2013).

\section{Diagnóstico}

O diagnóstico é feito através do histórico de uso de medicamentos, associados aos sinais clínicos, exame oftalmoscópico de fundo de olho e eletrorretinografia. Nesses exames, é relatada a presença de degeneração de retina, aumento da refletividade da zona tapetal, atenuação dos vasos retinianos entre outras alterações causadas pelo uso de fluorquinolonas. Na histopatologia, os pacientes apresentam degeneração da retina, perda difusa das camadas de células fotorreceptoras, hipertrofia e proliferação do epitélio da retina (FORD et al.,2007; CAVALCANTE et al. 2009).

Conforme Carneiro Filho (2004), o exame de fundoscopia ou oftalmoscopia é utilizado para visibilização do fundo do olho após a dilatação da pupila. Possui as formas direta e indireta, entretanto a mais usada na rotina é a forma direta, devido à maior facilidade no manuseio e ao custo do mais acessível do oftalmoscópio direto. Gellat (2003) relata que, entre as estruturas que se analisam neste exame estão o disco óptico, a vascularização retiniana e a porção tapetal. Entre as alterações descritas estão a refletividade tapetal, atenuação dos vasos retinianos, manchas de ferrugem pelo fundo tapetal e alterações de pigmentação (GELLAT et al., 2001).

A eletrorretinografia é o registro e análise da atividade da retina quando excitada pela luz. Sua importância ocorre por tratar-se de meio diagnóstico objetivo, não invasivo, capaz de avaliar a função retiniana, detectando precocemente lesões nas suas camadas mais externas. A luz para estimulação é colocada perto do olho, e as respostas aos flashes de luz são gravadas usando três eletrodos. O eletrodo ativo (da gravação) é acoplado geralmente a uma lente de contato colocada na córnea. Dois outros eletrodos são colocados na pele para reduzir a interferência elétrica (CARNEIRO FILHO, 2004; NEDEV; SIMEONOVA, 2017). 
Os sinais gravados da ERG são analisados avaliando a amplitude e a latência (sincronismo) de dois componentes principais: a onda "A" é a primeira deflexão negativa do sinal, e é indicativa da resposta do fotorreceptor. É seguida por um pico grande, positivo, a onda "B", que é gerada na camada intermediária da retina (bipolar e células de Müller) (CARNEIRO FILHO, 2004; NEDEV; SIMEONOVA, 2017).

\section{Diagnóstico diferencial}

É importante a diferenciação de outras retinopatias em gatos que podem apresentar a mesma sintomatologia, tais como a Atrofia Progressiva Retiniana (APR), que ocorre devido a uma deficiência na fosfodiesterase guanosina monofosfato cíclico, sendo hereditária na raça Abissínia, a doença se manifesta por midríase e nistagmo, progredindo para refletividade tapetal, atenuação de vasos sanguíneos e perda da pigmentação (LAUS et al., 2004; SAMPAIO et al. , 2015).

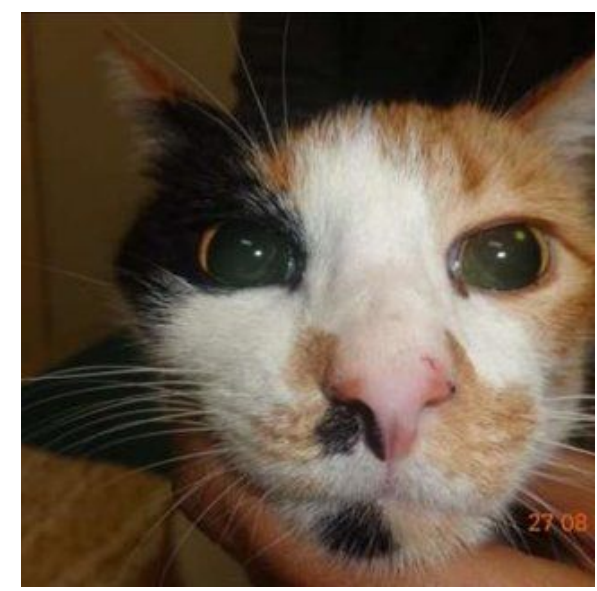

FIGURA 5: Gato com Atrofia Progressiva de Retina, evidenciando midríase. FONTE: SAMPAIO et al., (2015).

Antes das rações serem suplementadas com taurina era comum a ocorrência de degeneração retiniana central, caracterizando-se por uma área focal de hiperreflexibilidade tapetal no fundo do olho temporal progredindo até a atrofia difusa por toda retina. Os animais afetados, demonstram sinais de cegueira quando a lesão está em estado avançado. Entretanto, atualmente, este tipo de causa de degeneração de retina é extremamente rara (SHERDING; STEPHEN, 2013).

Deve-se considerar outras possibilidades para causa de cegueira aguda em gatos e que fazem (ou fizeram) uso de enrofloxacino por doença do trato urinário. Isso porque os felinos possuem uma maior propensão a apresentar descolamento de retina e outras alterações oftálmicas secundárias ao aumento da pressão arterial sistêmica, que, por sua vez pode ser vista em animais com doença renal crônica (LAUS et al., 2004).

\section{Tratamento}

Não existe tratamento especifico, para a degeneração de retina por enrofloxacino, sendo indicada a interrupção imediata do fármaco assim que for feito o diagnóstico. Alguns gatos podem recuperar uma parte da visão se a administração da droga for interrompida imediatamente, outros irão continuar cegos. Também ocorrem casos em que, se o diagnóstico for feito rapidamente, pode ocorrer um 
certo grau de recuperação da visão (ANJOS; BRITO,2009; CAVALCANTE et al. 2009).

Para evitar e minimizar a toxicidade retiniana em gatos deve-se prescrever alguns fármacos em substituição do enrofloxacino, como o marbofloxacino ou pradofloxacino quando necessário. Além do mais a dose para qualquer fluorquinolona não deve exceder a recomendada pelo fabricante evitando o uso parenteral e tratamentos prolongados principalmente em animais que se enquadram nos fatores predisponentes (LITTLE, 2016).

A recomendação é a utilização do antibiograma para infecções graves ou recorrentes, para pesquisa de qual antimicrobiano será eficaz. Em casos que o enrofloxacino for utilizado a dose diária deve ser de $2,5 \mathrm{mg} / \mathrm{kg}$, via oral a cada 12 horas, e evitar administração via intravenosa, monitorando o fundo de olho no período do tratamento. Caso seja necessária uma dose maior, recomenda-se um acompanhamento oftálmico. Se for observado início de midríase, deve-se suspender imediatamente o tratamento (GELATT et al., 2001; SOUZA; AMORIM, 2008).

\section{CONSIDERAÇÕES FINAIS}

Conclui-se primariamente que a degeneração de retina associada ao uso de enrofloxacino é mais decorrente do uso de terapêuticas errôneas associadas a este fármaco nos gatos, do que a fatores predisponentes diretamente ligados ao animal. Devido a não existência de um tratamento eficaz, a profilaxia ou interrupção imediata são as melhores opções.

É fato que são feitos diversos estudos acerca dos fatores predisponentes que causam este tipo de retinopatia, mas em sua maioria, se desconhece uma associação única de causa ao enrofloxacino. No entanto, os achados bibliográficos sugerem alguns fatores de risco que podem predispor os gatos à degeneração retiniana: altas doses ou altas concentrações plasmáticas da droga; infusão intravenosa rápida; longas administrações, idade, exposição a luz, interações medicamentosas, patologias que favorecem o acúmulo nos tecidos moles, ou afetam a eliminação pelos rins; e alterações metabólicas.

A maioria dos casos de intoxicações e/ou reações adversas, que acontece nos gatos, são resultantes do desconhecimento das diferenças de metabolização de medicamentos e da fisiologia dos felídeos. A interrupção da administração de enrofloxacino pode fazer com que alguns pacientes recuperem uma parte da visão, mas outros gatos continuam cegos. A administração do enrofloxacino, quando indicada, pode ser utilizada com mínimos riscos quando alguns detalhes forem considerados, como dose mínima e exata para o peso de cada paciente. Deve-se evitar interações medicamentosas, a fim de diminuir o risco de degeneração da retina nos felinos.

Dessa forma, os profissionais médicos veterinários deverão ter em mente que, os protocolos farmacológicos utilizados nos felinos não se baseiam nas doses recomendadas para cães. É importante ressaltar que devem ter o conhecimento de que os gatos não respondem da mesma forma que os canídeos, quando submetidos a certos medicamentos, pelo metabolismo diferenciado na ausência de enzimas ou diferenciações entre elas que provocam uma absorção mais lenta de uma droga. 


\section{REFERÊNCIAS}

ANDERSON, M. I.; MACGOWAN, A.P.; Development of the Quinolones. Journal of Antimicrobial Chemotherapy, v. 5, n.1, p. 1-11. Bristol/ England, 2003. Disponivel em: < https://www.ncbi.nlm.nih.gov/pubmed/12702698>. doi: 10.1093/jac/dkg212

ANDRADE, A.L. Semiologia do sistema visual dos animais domésticos. In: FEITOSA, F.L.F. Semiologia Veterinária a arte do diagnóstico. 2ed. São Paulo: Roca, 2008. p 690-718.

ANJOS, T. M.; BRITO, H. F. V. Terapeutica felina: diferenças farmacológicas e fisiológicas. Revista Cientifica de Medicina Veterinária - Pequenos Animais de Estimação, v. 7, n. 23, p. 554-567. 2009. Disponível em: < http://medvep.com.br/wpcontent/uploads/2016/04/Artigo174.pdf>

ASASHIMA, T.; HORI, S.; OHTSUKI, S.; TACHIKAWA, M.; WATANABE, M.; et al. ATP - Binding cassette transporter G2 mediates the efflux of phototoxins on the luminal membrane of retinal capillary endothelial cells. Pharmaceutical Research, v.23, n.6, p. 1235-1242. 2006. Disponivel em: < https://www.ncbi.nlm.nih.gov/pubmed/16715370>. doi: 10.1007/s11095-006-0067-2

BARCELLOS, H. H. A.; OLIVEIRA, S. T.; ALVES, L. P.; MOTTA, A. C.; ROCHA, F. R.; et al. Intoxicação por enrofloxacina em um cão da raça Pinscher Miniatura: relato de caso. Arquivo Brasileiro de Medicina Veterinária e Zootecnia, v. 58, n. 1, p. 39-43, 2006. Disponível em: < http://www.scielo.br/scielo.php?script=sci_arttext\&pid=S0102-09352006000100007>. doi: 10.1590/S0102-09352006000100007

CARNEIRO FILHO, L. Oftalmologia Veterinária: clinica e cirurgia. São Paulo: Roca, 2004, p. 15-26.

CAVAlCANTE, L. F. H.; GOUVÊA, A. S.; MARQUES, J. M. V. Degeneração retiniana em gatos associada ao uso de enrofloxacina - artigo de revisão. Acta Veterinaria Brasilica, v. 3, n. 2, p. 62-68. 2009. Disponível em: < https://periodicos.ufersa.edu.br/index.php/acta/article/download/1198/715>. doi: 10.21708/avb.2009.3.2

CUNNINGHAM, J.G. Tratado de Fisiologia Veterinária. 3 ed. East Lansing, Michigan; Guanabara Koogan, 2004.

FORD, M.M.; DUBIELZIG, R.R.; GIULIANO, E.A.; MOORE, C.P.; NARFSTROM, K.L. Ocular and systemic manifestations after oral administration of high dose of enrofloxacin in cats. American Journal of Veterinary Research, v.68, n.2, p.190202, 2007. Disponivel em: <https://www.researchgate.net/publication/6534574>. doi: 10.2460/ajvr.68.2.190

FORESTI, G. R. Enrofloxacino: desenvolvimento de métodos analíticos e perfil de dissolução baseado em dados in vivo. 2015, $121 \mathrm{f}$. In: Dissertação (Mestrado em Ciências Farmacêuticas). Pós-graduação em Ciências Farmacêuticas, Universidade Federal do Pampa - Uruguaiana, RS. Disponível em: 
<http://dspace.unipampa.edu.br:8080/bitstream/riu/525/1/Gabriela\%20Ribas\%20For esti.pdf>

GELATT, N.; WOERT A.; KETRING, K.I.; ANDREW, S.E.; BROOKS, D.E.; et al. Enrofloxacin-associates retinal degenerations in cats. Veterinary Ophthalmology, v.4, n. 2, p. 99-106. 2001. Disponível em:< https://www.ncbi.nlm.nih.gov/pubmed/11422990>.

doi:10.1046/j.14635224.2001.00182.x

GELATT, K.N. Doenças e cirurgias do segmento posterior no cão. In:

Manual de oftalmologia veterinária. Barueri: Manole, p.253-294, 2003.

GELATT, K. N.; GILGER, B.C.; KERN, T.J. Veterinary Ophthalmology. 5 ed. Ames, lowa. Wiley-Blackwell, 2013.

GURBAY, A.; GONTHIER, B.; SIGNORINI ALLIBE, N. Ciprofloxacin induced DNA damage in primary culture of rat astrocytes and protection by vitamin $E$. Neurotoxicology, v.27, n. 1., p.6-10, 2006. Disponivel em: < https://www.sciencedirect.com/science/article/pii/S0161813X05000896>.

doi:10.1016/j.neuro.2005.05.007

HIGGINS, P.G.; FLUIT, A.C.; SCHMITZ, F.J. Fluoroquinolones: structure and target sites. Current Drug Targets, v.4, n. 2, p.181-189, 2003. Disponivel em: <https://www.ncbi.nlm.nih.gov/pubmed/12558069>. doi:10.2174/1389450033346920

KLEIN, B.G. Tratado de Fisiológica Veterinária. 5.ed. Rio de Janeiro: Elsevier, 2014. 1599 p.

LAUS, J.L.; SOUSA, M.G.; CABRAL, V.P.; MAMEDE, F.V.; TINUCCI-COSTA, M. Uveodermatologic syndrome in a Brazilian Fila dog. Veterinary Ophthalmology, v. 7, n. 3, p. 193-196, 2004. Disponível em: < https://www.ncbi.nlm.nih.gov/pubmed/15091328>. doi: 10.1111/j.14635224.2004.04023.x

LEITE, A. G. B.; OLIVEIRA, D.; BARALDI-ARTONI, S. M. Morfologia do Sistema Ocular dos Animais Domésticos. ARS Veterinária, v. 29, n. 1, p. 42-51. 2013. Disponível em: < http://arsveterinaria.org.br/index.php/ars/article/view/504>. doi: 10.15361/2175-0106.2013v29n1p42-51

LITTLE, S. E. Toxicologia. In: LITTLE, S. E. O Gato: Medicina Interna. Rio de Janeiro: Roca, 2016, cap. 31, p. 880-899.

MELO, I. M. F.; SILVA, W. E.; TEIXEIRA, A. A.C.; WANDERLEY-TEIXEIRA, V.;BARRETO, S. B. F. P.; et al. Efeito da enrofloxacina sobre a interação blastocisto endométrio e seu reflexo no desenvolvimento placentário e fetal em ratas. Arquivo Brasileiro de Medicina Veterinária e Zootecnia, v. 66, n. 5, p. 1406-1412. 2014. Disponível em: < http://www.scielo.br/pdf/abmvz/v66n5/0102-0935-abmvz-66-0501406.pdf>. doi: 10.1590/1678-5594 
MILLER, P. E. The Eye and Vision. In: MAGGS, D. J.; MILLER, P. E.; OFRI, R. Slatter's Fundamentals of Veterinary Ophthalmology. Saunders, Elsevier, 2017. Cap. 1, p. $1-19$.

NEDEV, V.; SIMEONOVA, G. The normal electroretinogram in adult healthy Bulgarian hound dogs. Revue de Médecine Vétérinaire, v. 168, n. 4-6, p. 102-107, 2017. Disponível em: < https://www.revmedvet.com/2017/RMV168_102_107.pdf>.

ORIÁ, A. P.; PINHEIRO, A. C. O.; ALMEIDA, D. S.; FURTADO, M. A.; PINNA, M. H. Microbiota normal bacteriana da conjuntiva ocular - Revisão de Literatura. Medicina Veterinária, v. $5, \quad$ n. 3 , p. 16-21. 2011. Disponível em: < http://www.journals.ufrpe.br/index.php/medicinaveterinaria/article/viewFile/640/519>.

SAMPAIO, M. O. B. MONTIANI-FERREIRA, F.; SEABRA, N. M. Atrofia Progressiva de Retina em um gato sem raça definida, tendo como principal diagnóstico diferencial a retinopatia tóxica - relato de caso. Archives of Veterinary Science, v. 20, n. 3, p. 100-109, 2015. Disponível em: < https://revistas.ufpr.br/veterinary/article/view/40058>. doi: 10.5380/avs.v20i3.40058

SAMUELSON, D.A. Ophthalmic Anatomy. In: GELATT, K.N.; GILGER, B.C.; KERN, T.J. Veterinary Ophthalmology. 5. ed, v. 1. New Jersey: John Wiley \& Sons, Inc., 2013. p. 39-170.

SHERDING, B.; STEPHEN, J.B. Manual Saunders clinica de pequenos animais. São Paulo: Roca, 2013, p.1410-1411.

SILVA, J. M. B.; HOLLENBACH, C. B. Fluorquinolonas x Resistência Bacteriana na Medicina Veterinária. Arquivos do Instituto Biológico, v. 77, n. 2, p. 363-369. $2010 . \quad$ Disponível <http://www.biologico.sp.gov.br/uploads/docs/arq/v77_2/silva1.pdf>.

em:

SILVA, J.V.; FERREIRA, B.F.A.; PINTO, H.S.R. Princípios da oftalmologia. Anátomo-histologia funcional do olho. Universidade Federal do Ceará, 2013.

SOUZA, H. J. M. Coletâneas em Medicina e Cirurgia Felina. Rio de Janeiro: L. F. Livros, 2003.

SOUZA, H.J.M.; AMORIM, F.V. Terapêutica Felina: Cuidado com o Uso de Fármacos em Gatos. In: ANDRADE, S. F. Manual de Terapêutica Veterinária. 3. Ed. São Paulo: Roca. 2008. cap 2. p. 648-659.

SPINOSA, H. S.; GÓRNIAK, S. L.; BERNARDI, M. M. Farmacologia aplicada à medicina veterinária. 5. Ed. - Rio de Janeiro: Guanabara Koogan, 2011.

SPINOSA, H.S.; GORNIAK, S. L.; BERNARDI, M.M. Farmacologia Aplicada a Medicina Veterinária. 6. Ed. Rio de Janeiro: Guanabara Koogan, 2017. p.721-727.

TAVARES, W. Antibióticos e Quimioterápicos para o Clínico. 3ed. São Paulo: Atheneu, 2014. p.371. 
TREPANIER, L. A. Diretrizes e precauções para Terapia Medicamentosa em Gatos. In: LITTLE, S. E. O Gato: Medicina Interna. Rio de Janeiro: Roca, 2016, cap. 4, p. 38-49.

TURNER, S.M. Série Clínica Veterinária na Prática - Oftalmologia Veterinária em Pequenos Animais. 1 ed. Rio de Janeiro, RJ, 2010.

WIEBE, V.; PHARM, D.; HAMILTON, P. Fluoroquinolone-induced retinal degeration in cats. Journal of the American Veterinary Medical Association, v.221, n.11, p.1568-1571. $2002 . \quad$ Disponivel em: $<$ https://avmajournals.avma.org/doi/abs/10.2460/javma.2002.221.1568?journalCode =javma $>$. doi: $10.2460 / j a v m a .2002 .221 .1568$ 